\title{
A Review of the Research on the National Identity Education of Hong Kong Youth
}

\author{
Yunyi Liu* \\ Beijing New Oriental Foreign Language School at Yangzhou, Yangzhou, 225000, China \\ *Corresponding Author.Email: guanghua.ren@gecacdemy.cn
}

\begin{abstract}
Hong Kong's youth have defects in their national identity, its ideological risks have always existed and have continued to this day. This paper reviews studies about Hong Kong national identity education after the return. Through existing research on the policy reforms, curriculum setting, teacher quality and public attitudes of Hong Kong's national identity education, this research believes that the educational content, main body of education, and educational management system of the Hong Kong Special Administrative Region have not yet escaped the shadow of colonial rule. As a conclusion, this article proposes that although Hong Kong is now facing difficulties with national education, it is important for Hong Kong to establish a national education system with patriotism and love for Hong Kong as well as strengthen the professional ethics and ethical responsibility of teachers.
\end{abstract}

Keywords: Hong Kong, National education, National identity, Policy.

\section{INTRODUCTION}

Former studies show that Hong Kong's national education should focus on identifying with contemporary China. For example, Deng Fei, vice chairman, Hong Kong Federation of Teachers, once said that to enhance national identity, it is necessary not only to start from the government and policies, but also to strengthen education and social disseminate. However, Hong Kong's education has not changed with the return. In recent years, the sense of national identity of some Hong Kong youth is weak and even missing. Not only this state has not changed fundamentally, but also has gradually deteriorated. National education has not been recognized and developed steadily in a short period of time. Due to the lack of national education, there have been frequent political incidents and riots among youth, which has reached an alarming degree. Furthermore, the teachers' problems, such as the political repudiation of contemporary China and the inappropriate personal feelings about historical events. But the problem of teachers cannot be solved perfectly in recent years. It is important to study the national education. Because it allows more students to walk into the national culture, experience the development of the country, and recognize their own nation. Thus students can gradually form a sense of identity with the Chinese nation and the motherland, foster a new generation of people who love Hong Kong and love the country, so as to ensure the steady progress of the cause of "one country, two systems" in Hong Kong. Thus, this paper will systematically review the process of transforming civic education to national education and the policies promulgated by the government. On the other hand, it will also make a detailed explanation of the school's education and teachers' problems with suggestions at the end. In order to provide suggestions for the development of Hong Kong national identity education, this article attempts to explore the reasons why Hong Kong youth lack a sense of national identity from the perspective of national education.

\section{POLICY REFORM ON NATIONAL IDENTITY EDUCATION ADOPTED BY HONG KONG}

According to the education and the policies introduced after the return of Hong Kong, it can divide into three steps: The stage of national education in civic education, The stage of transition from "civic education" to "national education", National Education disturbance. 


\subsection{National identity in civic education}

In the year of 1996, the Hong Kong government promulgated the second "Guide to National Education Curriculum". Based on the first "Guide to National Education Curriculum" promulgated in 1985 determined above the tone of "civic education essentially includes political education" [1]. The educational purpose is to understand the main values and principles of a democratic society, and to recognize the rights and duties of citizens [2]. It was the first policy that put forward a sense of Chinese identity. Also, in the 2001, the Curriculum Development Council promulgated the "Learning to Learn-The Way of Curriculum Development", which emphasized the cultivation of students' national identity through understanding the Chinese cultural elements that contained in various learning fields. In 2004, the government established a national education task force in order to promote the national education outside the school. Since then, on the one hand, the government and the National Education Task Force have used various activities such as promotional videos, root-seeking tours, cultural and sports celebrities to visit Hong Kong and other activities, especially young people, to foster home and country feelings. On the other hand, the education department and the school deepens students' understanding of Chinese culture through subjects such as Chinese Language, Chinese Literature, and Comprehensive Humanities (Chinese History and Geography) [3].

\subsection{The stage of transition from "civic education" to "national education"}

The "Newly Revised Curriculum Framework for Ethics and Civic Education" was released in 2008. It clearly put forward the content of "strengthening national education", developing the policy of "national education" accelerates the process. In 2010, In the "2010-2011 Policy Address", occur the phenomenon that set up the Nation Education as a independent compulsory course and executed in 2012. In 2012, the "Moral Education and National Education Curriculum Guidelines (Primary One to Secondary Six)" was launched, and in June of the same year, the "Chinese Model and National Conditions Special Education Manual" was launched. It can be seen from this that the essence of "civic education" in Hong Kong is to promote "national education". Thus, based on Improving the "civic education" curriculum theory step by step to achieve the goal of promoting "national education" [1].

\subsection{National Education Disturbance}

In April 2012, the Hong Kong Education Bureau published the "Guide to the Curriculum of Moral Education and National Education", which believed that curriculum development is a continuous process of optimization. Therefore, it proposed to establish the Moral Education and National Education subject. The content uses lifetime as the context of learning, cooperating with learning subjects, learning activities, student development plans, school environment in order to consolidate students' morality and national quality, and promote students' all-round development. Subsequently, the "Chinese Model National Conditions Special Education Manual" was published in July 2012. It brought the discussion of the National Education Section to the culmination. Some Hong Kong citizens, parents, teachers, and scholars believed that the content of the manual was mostly a description of the achievements of the People's Republic of China. The content tends to be positive, avoiding controversial part. Thus, it has the element of imprisoning students' thinking. In July 2012, a large-scale demonstration took place in the education sector in Hong Kong, which aroused the attention of all parts of the country. A large number of Hong Kong citizens led their children to march in the streets, opposing and asking to withdraw this subject [4].

\section{CURRICULUM AND TEACHING EFFECTIVENESS OF NATION IDENTITY IN SCHOOL}

\subsection{Promotion of National Identity Education and Curriculum Setting}

According to the requirements of the "Basic Education Curriculum Guidelines". The goal that the school conducts moral education and citizen education in order to help students develop comprehensive values and positive attitudes. Also, according to the needs of individual and group development of students, Hong Kong's actual situation and the global situation has established five values and attitudes to cultivate students' perseverance like respecting for others, a sense of responsibility, national identity and commitment through moral education and civic education. In order to achieve good results in civil education, Hong Kong's civil education attaches great importance to the development of civil education through various channels. At present, Hong Kong schools generally cultivate national education in citizen education through the following 3 ways. First, national identity education is an important teaching goal in formal courses. The school arranges civic education as an independent course in order to introduce national identity education. For example, in "Social Studies", "Economics and Public Affairs Division", these courses begin with the origin of the Hong Kong issue, allowing students to understand the fact that Hong Kong has been the territory of China since ancient times, focusing on cultivating students' correct values, positive attitudes and national identity 
[5]. Second, the field of study enables students to really understand the social culture of the mainland. Some related value thinking and activities, such as teaching students to understand and appreciate the development and achievements of the Chinese nation's history, literature, science, sports, art and so on This kind of schoolwork allows students to actively explore issues related to national identity. Meanwhile, the educational content of national identity is expanded since it can be included in many subjects. For example, social and humanities education, Chinese education, science education, physical education and art education or other learning fields [5]. Third, carrying out practical activities such as arranging students to participate in voluntary social service plans, this can cultivate their spirit of commitment and responsibility. For example, visiting the Great Wall exhibition held by the Hong Kong Museum of History, this can stimulate students' interest and enthusiasm for Chinese history and culture [5].

\subsection{The insufficient teaching effectiveness of national identity education}

Although education in Hong Kong is changing, due to the long-term colonial influence, vestiges of colonial ideology still exist in Hong Kong society, such as teachers, and it will not be able to make good improvements in a short period of time. Teacher's personal political views can easily influence student thinking. In 2004, in order to understand the teachers' attitudes towards national education, the Hong Kong Federation of Education Workers randomly surveyed 250 teachers in primary and secondary schools. The results showed that although most teachers believed that national conditions education should be strengthened, there were $62 \%$ of teachers do not think that it is within the scope of their duties to transmit positive values and cultivate students' sense of national identity. This essentially means that more than half of the teachers who teach values education courses aimed at fostering national identity at the school level reject "national identity" as political ideological propaganda under the pretext of so-called "political neutrality" during the colonial period. In 2009, the general Education department was quickly established and became one of the core subjects of the new senior high school curriculum, while the general education class quickly became an important field for students to receive national education, also when discussing Chinese social and cultural issues, the teaching materials that teachers choose on their own about national quality are basically labeled judgments about Chinese people being "dirty, messy and noisy" When discussing Chinese political issues, teachers' self-selected teaching materials are full of stigmatizing accusations against Democracy and human rights in China from the perspective of Western "universal values" [3].

\section{THE RESISTANCE FROM SOCIAL GROUP OF NATIONAL IDENTITY EDUCATION}

When the "The Chinese Model: Teaching Manual on National Conditions" is exposed, it immediately caused a "state religion turmoil." First, tens of thousands of people marched and demonstrated, followed by college students' "Union School Anti-National Religion", and even set the slogan "Anti-colonial and Anti-National Religion." opponents regard "National Education and Science" because they think it is a brainwashing education and enslavement education, not only this, but also believe that it will undermine students' independent thinking ability and autonomy [3]. The parade began at $3 \mathrm{pm}$, with 19000 people in the beginning, and the highest peak reached 32000. However, only identity with Chinese culture doesn't necessarily mean that you have a deep understanding and interest in traditional Chinese culture. On the contrary, after the "opposition to the National Education Section" in 2012, the Hong Kong opposition has developed to openly promote the "locust theory", "China theory" and "Hong Kong national theory" and other naked and extreme remarks, finally evolved into separatist activities. Even In 2019, there was a large-scale "black storm" impact [6].

\section{CONCLUSION}

This article summarizes a series of issues in Hong Kong's national identity education in policy formulation, school education practice, and public awareness. This provides a reference for the development of Hong Kong's national education. In summary, this article believes although Hong Kong is now facing difficulties with national education, it is important for Hong Kong to establish a national education system with patriotism and love for Hong Kong as well as strengthen the professional ethics and ethical responsibility of teachers.

\subsection{National education is difficult to implement in Hong Kong}

Although Hong Kong Education Deployment has implemented a series of reform after the reunification, and it has also made effective progress. However, the history of colonial rule and colonial education for a century and a half has imprinted Hong Kong with profound social thoughts and values which leads Hong Kong's education to face conflicts of ideas and system defects. Bringing about some educational dilemmas and educational mistakes. As this paper mentioned above, After the reunification, although Hong Kong emphasized national education, and integrate "Moral Education and Civic Education" as a key project into the basic education reform, there are many deficiencies of national education. For example, the content of the course is less related to the history and political system 
of the Mainland China. It emphasizes too much on the difference between mainland and Hong Kong, which is not conducive to the formation of the concept of an integrated country. Moreover, the education administrative department's position and attitude towards national identity education are not clear and firm enough because they lack regulatory power of school curricula and teaching practices. Although the proposal of "Moral Education and Civic Education Curriculum" was proposed in 2012, the resulting "national education storm" shelved the establishment and implementation of the national education subject and changed the form and content of national education that the school decided to set up on its own. Since schools have the right to make decisions independently, the policies and instructions from the education authorities can hardly prohibit such behavior and unify order. The absence of unified curriculum standards and the insufficient of unified teaching materials have generally weakened China's National Conditions Education, so that students have little understanding of the country's history, culture, political system, and development process, and naturally it is difficult to form basic national consciousness.

\subsection{Enhance young people's knowledge of China}

The end of colonial rule does not mean that the history, culture, and heritage of the colonial period's traditional habits can disappear immediately. After more than a century of implantation of Western values, some Hong Kong people prejudiced the development of the mainland, which caused the alienation and separation, even fear and incomprehension. But, in Hong Kong, according to the complex social environment that has undergone unique historical changes, national identity education must not only include the level of local cultural identity, but also need to cultivate their understanding of contemporary Mainland China. However, national identity in Hong Kong has not achieved its goal among the new generation of young people. Even then, under the interference of the Hong Kong opposition and some hostile forces abroad, deviation of values emerges in some younger generations. There have been many riots in recent years, and some even put forward the slogans of Hong Kong independence. These street movements intensified the pan-political atmosphere of Hong Kong society, and at the same time caused Hong Kong's social environment and social psychology to be damaged and troubled in varying degrees. However, what needs to be deeply vigilant about is that most of the participants in these events are the younger generation. On the surface, it is due to the immature minds of young people, they can't rationally view the complex and changeable political environment and social issues. But in essence, they have experienced deviations in their ideological understanding, lacking national identity awareness and identity confusion. This worrying phenomenon will seriously harm the stability and the development of Hong Kong society. Therefore, this situation must not be ignored.

\subsection{Improving the effectiveness of Hong Kong teachers' national identity education}

There is no doubt that the schoolteachers play important roles in national identity education. As said above, many teachers believe that cultivating students' sense of national identity is not within the scope of their educational responsibilities, also some of them have their personal political color in some historical events. Therefore, For the Hong Kong government, the primary task now is to promote the improvement of teacher employment and guide the healthy development of teachers. At the same time, they need to cultivate a team of outstanding teachers who are patriotic, have a sense of national identity, and love Hong Kong. First, Strengthen the construction of teachers' ethics, and regard "love the country and love Hong Kong" as the primary condition and necessary quality for teachers' qualifications. As the guide of education and the proponent of national spirit, teachers should not only strengthen their sense of responsibility, but also pay attention to the individual's moral cultivation and internal consciousness. Constantly cultivate the professional quality of "model" and professional quality of "teacher", and gradually form the educational leadership that can lead and influence the development of students. On the other hand, they should also consciously integrated value education into the education and teaching process, carrying out correct direction guidance at appropriate times, also focusing on cultivating students' subjective moral personality, helping them to think and learn rationally through practical issues and discuss controversial topics in order to enhance their political literacy and critical thinking ability. Second, a systematic and complete training program should be provided for teachers to get know more about the Constitution. Basic Law and Hong Kong's National Security Law. Also conduct rotation training for all teachers in Hong Kong to cultivate the sense of patriotism and loyalty. Not only patriotism and loyalty but also the awareness of national security. Improving the exchange and inspection mechanism for teachers that from Hong Kong universities, schools, and kindergartens to the Mainland China. Making the exchange and inspection to the Mainland China as a necessary part of teacher training and assessment. By organizing Hong Kong teachers to study and practice in the Mainland China, it will increase teachers' awareness of national conditions and enhance teachers' national pride, the effectiveness of education. Third, implementing the Hong Kong National Security Law to provide legal protection for the construction of a team of 
patriotic and Hong Kong teachers. The Hong Kong government should take necessary measures to strengthen publicity, guidance, supervision and management. The Hong Kong Special Administrative Region Safety knowledge is included in the assessment that content of teachers and practitioners. Teachers are strictly controlled to prevent people who promote "Hong Kong independence" or have this tendency from entering the education field.

\section{REFERENCES}

[1] ShengQi L, (2016). Hong Kong School Civic Education Research. China youth university of political studies.

[2] MingYuan G, (1986). Education Dictionary: Shanghai Education Publishing House.

[3] Jie C, (2021). Research on the dilemma of "national identity education" of Hong Kong people since the return of Hong Kong. Education science in China.

[4] ZhiMing G, YuDan S, (2014) Analysis on the policy evolution of Hong Kong civic education in the past twenty years. The modern education general.

[5] FuShou H, (2015). Historical changes of civic education in primary and secondary schools in Hong Kong. Youth research.

[6] Fei D, (2013), Hong Kong's national education should focus on identifying with contemporary China. Global Times. 